Meta

Journal des traducteurs

Translators' Journal

\title{
Terminologie alimentaire
}

\section{Jean-François Pelletier}

Volume 25, numéro 2, juin 1980

URI : https://id.erudit.org/iderudit/003810ar

DOI : https://doi.org/10.7202/003810ar

Aller au sommaire du numéro

Éditeur(s)

Les Presses de l'Université de Montréal

ISSN

0026-0452 (imprimé)

1492-1421 (numérique)

Découvrir la revue

Citer cet article

Pelletier, J.-F. (1980). Terminologie alimentaire. Meta, 25(2), 257-258.

https://doi.org/10.7202/003810ar

Ce document est protégé par la loi sur le droit d'auteur. L'utilisation des services d'Érudit (y compris la reproduction) est assujettie à sa politique d'utilisation que vous pouvez consulter en ligne.

https://apropos.erudit.org/fr/usagers/politique-dutilisation/
Cet article est diffusé et préservé par Érudit.

Érudit est un consortium interuniversitaire sans but lucratif composé de l'Université de Montréal, l'Université Laval et l'Université du Québec à Montréal. Il a pour mission la promotion et la valorisation de la recherche. https://www.erudit.org/fr/ 
TERMINOLOGIE ALIMENTAIRE*

\begin{tabular}{|c|c|c|}
\hline ANGLAIS & FRANÇAIS & DESCRIPTION \\
\hline \multirow[t]{2}{*}{$\begin{array}{l}\text { CONVENIENCE FOODS } \\
\text { (Sens } A \text { : quand il s'agit } \\
\text { d'un ensemble de mets } \\
\text { agencés) }\end{array}$} & $\begin{array}{l}\text { Soit: PLATS CUISINÉs } \\
\text { (n'exigeant pas d'être gardés } \\
\text { au frigo) }\end{array}$ & $\begin{array}{l}\text { Plats fait d'avance et qu'on peut servir } \\
\text { avec un minimum de préparation. } \\
\text { Ex. : Le «Beef \& Kidney Pie» d'Ogilvy, } \\
\text { présenté sous contenant métallique. }\end{array}$ \\
\hline & $\begin{array}{l}\text { Ou : PLATS CUISINÉS } \\
\text { SURGELÉS } \\
\text { (exigeant d'être gardés } \\
\text { au congélateur) }\end{array}$ & $\begin{array}{l}\text { Plats identiques aux précédents, mais } \\
\text { vendus à l'état surgelé. } \\
\text { Ex.: Les «TV dinners" et autres } \\
\text { produits du genre. }\end{array}$ \\
\hline \multirow[t]{2}{*}{$\begin{array}{l}\text { CONVENIENCE FOODS } \\
\text { (Sens } B: \text { quand il s'agit } \\
\text { d'un seul mets) }\end{array}$} & $\begin{array}{l}\text { Soit : ALIMENTS D'APPOINT } \\
\text { (n'exigeant pas d'être gardés } \\
\text { au frigo) }\end{array}$ & $\begin{array}{l}\text { Un seul aliment vendu comme } \\
\text { complément aux repas complets du type } \\
\text { «convenience foods». } \\
\text { Ex. : Fruits, légumes et desserts divers, } \\
\text { généralement présentés sous contenants } \\
\text { de verre ou de métal. }\end{array}$ \\
\hline & $\begin{array}{l}\text { Ou : SURGELÉS D'APPOINT } \\
\text { (exigeant d'être gardés au } \\
\text { congélateur }\end{array}$ & $\begin{array}{l}\text { Même genre d'aliments que ci-dessus, } \\
\text { mais vendus à l'état surgelé et sous } \\
\text { divers contenants (métal, verre, carton, } \\
\text { plastique). }\end{array}$ \\
\hline \multirow[t]{2}{*}{ FAST FOODS } & Soit : REPAS-MINUTE & $\begin{array}{l}\text {...quand le tout constitue un repas } \\
\text { complet, exigeant peu de préparation, } \\
\text { présenté dans un récipient jetable, avec } \\
\text { assaisonnements en sachets. }\end{array}$ \\
\hline & OU: PLATS-MINUTE & $\begin{array}{l}\text {...quand les éléments ne font qu'un seul } \\
\text { mets, rapidement préparé, et présenté } \\
\text { sous récipient jetable. }\end{array}$ \\
\hline FAST FOODS INDUSTRY & $\begin{array}{l}\text { Soit: RESTAURATION-MINUTE } \\
\text { (au choix) } \\
\text { Ou : RESTAURATION RAPIDE }\end{array}$ & $\begin{array}{l}\text { Secteur de l'industrie alimentaire, } \\
\text { spécialisé dans la fabrication et la vente } \\
\text { de repas-minute, ou encore, dans le } \\
\text { service de tels repas ou plats-minute. }\end{array}$ \\
\hline $\begin{array}{l}\text { FAST FOODS } \\
\text { RESTAURANT }\end{array}$ & RESTAURANT-MINUTE & $\begin{array}{l}\text { Établissement de restauration servant } \\
\text { surtout des repas-minute et des } \\
\text { plats-minute. }\end{array}$ \\
\hline FROZEN FOODS & ALIMENTS CONGELÉS & $\begin{array}{l}\text { Aliments vendus en contenants jetables, } \\
\text { mais à l'état congelé et qu'on doit } \\
\text { garder au congélateur. }\end{array}$ \\
\hline $\begin{array}{l}\text { DEEP FROZEN FOODS } \\
\text { (et ses synOnYmes :) } \\
\text { FAST FROZEN FOODS } \\
\quad \text { (et) } \\
\text { QUICK FROZEN FOODS }\end{array}$ & $\begin{array}{l}\text { Soit : ALIMENTS SURGELÉS } \\
\text { (au choix) } \\
\text { Ou : LES SURGELÉS }\end{array}$ & $\begin{array}{l}\text { Aliments vendus en contenants jetables, } \\
\text { comme ci-dessus, mais à l'état surgelé. } \\
\text { Note. La surgélation (appelée aussi } \\
\text { surcongélation) est simplement une } \\
\text { congélation ultra-rapide, faite à basse } \\
\text { température (entre }-20^{\circ} \mathrm{C} \text { et }-35^{\circ} \mathrm{C} \text { ). }\end{array}$ \\
\hline
\end{tabular}

* Lexique établi pour CULINAR 
DRY FROZEN FOODS
ALIMENTS LYOPHILISÉS

(Ex.: les sachets de soupes

Lipton, Knorr, etc.)
Aliments soumis à une congélation brutale et à très basse température (environ $-80^{\circ} \mathrm{C}$ ), puis déshydratés à fond, et présentés en contenants scellés. On sert en additionnant de l'eau.

Note: Différence entre les «CONVENIENCE FOODS» et les «FAST FOODS». Cette différence en est une d'utilisation des termes. Différence minime mais réelle, en français comme en anglais. On voudra donc en tenir compte, au moment voulu. Dire «convenience foods», c'est s'attacher au processus de fabrication de ces aliments, ou à leur état subséquent : plats cuisinés, aliments d'appoint, surgelés d'appoint. Dire «fast foods», c'est souligner clairement le processus de consommation des mêmes aliments : repas-minute, plat-minute, restauration rapide.

Jean-François Pelletier 